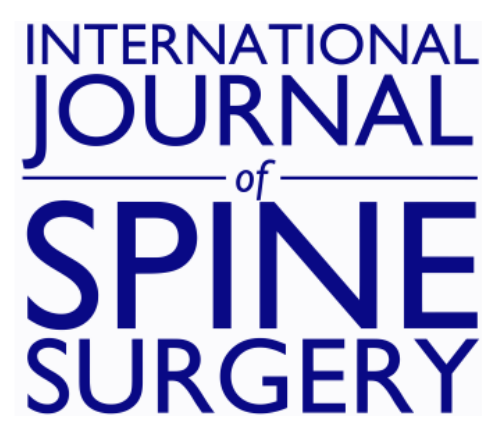

\title{
Safety and Efficacy With Augmented Second-Generation Perforated Pedicle Screws in Treating Degenerative Spine Disease in Elderly Population
}

\author{
LUIS ALVAREZ-GALOVICH, FELIX TOME-BERMEJO, ANA B. MOYA, IGNACIO \\ MAHILLO-FERNANDEZ, ANGEL R. PIÑERA, CHARLES L. MENGIS, JESUS M. GALLEGO, \\ FRANCISCO M. GARZÓN, MARIA G. RODRIGUEZ, SYLVIA SANZ and ALEJANDRO \\ PEIRO-GARCIA
}

Int J Spine Surg 2020, 14 (5) 811-817

doi: https://doi.org/10.14444/7115

http://ijssurgery.com/content/14/5/811

This information is current as of April 25, 2023.

Email Alerts Receive free email-alerts when new articles cite this article. Sign up at: http://ijssurgery.com/alerts 


\title{
Safety and Efficacy With Augmented Second-Generation Perforated Pedicle Screws in Treating Degenerative Spine Disease in Elderly Population
}

\author{
LUIS ALVAREZ-GALOVICH, MD, FELIX TOME-BERMEJO, MD, ANA B. MOYA, PA, IGNACIO \\ MAHILLO-FERNANDEZ, PHD, ANGEL R. PIÑERA, MD, CHARLES L. MENGIS, MD, JESUS M. \\ GALLEGO, FRANCISCO M. GARZÓN, MD, MARIA G. RODRIGUEZ, MD, SYLVIA SANZ, MD, \\ ALEJANDRO PEIRO-GARCIA, MD \\ Spine Service, Fundación Jimenez Diaz, Madrid, Spain
}

\begin{abstract}
Background: Degenerative spine disease is a common cause of low back pain in people age 65 years or older. Nonsurgical treatment is tried first, but if it is unsuccessful, surgery is advocated. This has special connotations for both underlying disease and the biomechanical characteristics of osteoporotic bone. We conducted an observational study to investigate the clinical and radiological outcome in patients in this age group with poor bone quality and degenerative lumbar instability treated with fusion using perforated pedicle screws augmented with polymethylmethacrylate (PMMA).

Methods: We collected prospective data on treatment, outcome, and patient characteristics from our institution's database. The primary outcome was a change in pain and physical function measured by the visual analog scale, the Core Outcome Measures Index, and the Oswestry Disability Index. Control participants were also analyzed for secondary complications such as hardware mobilization, fusion (as apparent on radiographs), and adjacent fractures or adjacent degenerative disc disease.

Results: We included 89 patients who underwent surgery between October 2015 and February 2018 at a mean age of 78 years (range, 67-88 years) and were then monitored for at least 12 months (range, 12-40 months). Findings on pain and function questionnaires showed improvement at 6 months after surgery, maintained at the final evaluation; $90 \%$ of patients had final score increases of $\geq 15$ points. No patient developed clinical complications secondary to PMMA leakages. One patient had nonunion and screw breakage. No other patient had clinical or radiological nonunion. Of the control participants, 6 had adjacent disc disease, with 2 of them requiring instrumentation extension. Six deep infections required surgical revision without removal of material.

Conclusion: PMMA-augmented cannulated pedicle screw instrumentation in spine fusion effectively and safely treats degenerative lumbar disease in patients who are age 65 years or older with poor bone quality.
\end{abstract}

New Technology

Keywords: pedicle screw augmentation, polymethylmethacrylate, osteoporosis, degenerative lumbar surgery, older patients

\section{INTRODUCTION}

Degenerative spine disease (DSD) is a condition among people age 65 years or older that can substantially affect mobility, function, and healthrelated quality of life. ${ }^{1}$ The cardinal symptoms of DSD are back and leg pain, and symptoms of lumbar spinal stenosis with neurogenic claudication, such as lower-limb pain and neurological symptoms that are exacerbated by walking and standing. ${ }^{2}$

First-line treatment is nonsurgical and may include a combination of drugs, exercise, manual therapy, lifestyle modification, and multidisciplinary rehabilitation. ${ }^{2}$ If such treatment is unsuccessful, however, surgery is advocated.

Lumbar spinal stenosis and DSD together are the most frequent indication for spine surgery in patients age 65 years or older, with there being 3 to 11.5 cases per 100,000 people per year. ${ }^{3}$ Its incidence is expected to increase as the size of the aged population increases. ${ }^{4}$ Worldwide, researchers have reported similar trends attributable to their country's particular demographics and health-care systems. In developed countries, such as England 
and the United States of America, dramatic increases in surgery for DSD have been identified. ${ }^{5,6}$

Patients who are age 65 years or older have an increased risk of complications in lumbar surgery, especially when they have a high degree of comorbidity and poor bone quality. 2,3,7 The technical difficulties and high rate of complications associated with osteoporotic bone fixation are well known. ${ }^{8}$ In addition, the torque and pullout strength of pedicle screws have a linear correlation with bone mineral density. ${ }^{9,10}$ Many screw augmentation techniques have been proposed; cemented polymethylmethacrylate (PMMA) augmentation appears to be the most effective method according to findings from biomechanical testing. ${ }^{11-16}$ The use of a second generation of perforated pedicle screws (PPSs) with more advanced forms of PMMA has probably been the cause of improvement over earlier results.

The purpose of the study we report here was to analyze the results of lumbar fusion using secondgeneration PPSs in patients age 65 years or older with poor bone quality.

\section{MATERIALS AND METHODS}

\section{Participants}

All 89 patients diagnosed with DSD and treated in our institution between October 2015 and February 2018 by spine fusion with second-generation PPSs were considered for our study and the data were prospectively recorded.

\section{Criteria for Patient Inclusion}

We included patients in our study if they met all of the following criteria:

- Inclusion in the Fundacion Jimenez Diaz Spine Data Registry

- Having poor bone quality

- Recipient of more than 12 months of follow-up care

- Consenting to the use of patient-reported data for research purposes

\section{Exclusion Criteria}

We excluded patients from our study if they met these criteria:

- Having undergone previous surgery

- Having more than 3 levels of fusion

\section{Outcome Measures}

The primary outcome for our study was a change in physical function score between the baseline and the follow-up evaluation at 12 months after surgery, as measured by the Oswestry Disability Index (ODI). ${ }^{17}$ The ODI assesses pain-related physical function in spine disorders. It has been tested extensively, has good psychometric properties, and is applicable in a wide variety of settings. The ODI contains 10 questions about how back or leg pain affects the ability to manage activities of daily life. Findings result in a score ranging from 0 to 100 , with higher scores reflecting worse pain and disability.

The secondary outcome of the study was a change in score on the visual analog scale (VAS) for pain between baseline and the 12-month followup evaluation.

\section{Core Outcome Measures Index}

In 1998, a multinational group of investigators studying back pain designed the Core Outcome Measures Index (COMI) to evaluate pain, function, generic health status or well-being, disability, and satisfaction. ${ }^{18}$ The ultimate goal of developing the COMI was to provide a standardized outcome assessment without an excessive burden of instruments or questions that make it difficult for patients to complete evaluation. The COMI was confirmed against well-validated instruments such as the Roland-Morris and the ODI for back-specific function, and the Medical Outcomes Study Short Form 36 (SF-36), its abbreviated form SF-12, and the EuroQol Quality of Life Scale for general health status. In 2006, a group validated the Spanish version of the COMI. ${ }^{19,20}$ The authors designed a prospective study to evaluate the reliability, validity, and responsiveness of the instrument for patients with subacute osteoporotic fracture (quick decrease in pain after treatment) and chronic low back pain (slow decrease in pain); they compared COMI scores with scores for the validated Spanish ODI, the SF-36, and the SF-12. They concluded that the COMI was useful for evaluating patient-based outcomes when the respondent burden is an important problem. Still, subscale scores must be further tested in other populations. In this case, we used to measure as a quality of life scale and patient satisfaction. 
All questionnaires discussed here either have been validated in Spanish or validated in their original language and translated into Spanish using scientific standards.

\section{Data Collection}

Data on age, sex, diagnosis, treatment, and previous spine surgery were collected from our institution's patient database. For each participant, serial radiological control images were also obtained and were analyzed for secondary complications such as adjacent fractures, hardware mobilization, and radiological evidence of nonunion.

All patients underwent a control 3-dimensional computed tomography (CT) scan at 6 months after surgery. If there was any doubt about the malpositioning of instrumentation or concern about leakage of cement in the control image, another scan was performed immediately after surgery. We evaluated screw positioning, and we used the classification devised by Yeom et $\mathrm{al}^{21}$ to assess any cement leakage. Fusion was assessed using CT scan reconstruction images. For a segment to be categorized as fused, there had to be a continuous bony bridge between the transverse processes or at the lateral side of the facet joints. If there was only unilateral facet-joint fusion, questionable bilateral facet fusion, or a possible presence of cleft in the bony bridge, the fusion was categorized as doubtful. Segments with a clearly definable cleft in the bony bridge, questionable fusion in 1 facet joint, or no contralateral fusion or with desorption of most of the fusion mass were classified as nonunion. ${ }^{22}$

\section{Surgical Technique and Care}

A standard open posterior midline approach to the lumbar spine was used. Laminectomy or hemilaminectomy, associated or not with facetectomy, was performed before fusion in patients with foraminal or central canal stenosis.

Freehand pedicle screw insertion was used in all cases. A standard rounded pedicle finder was progressively introduced until it reached the midheight anterior one-third of the vertebral body. Cannulated pedicular screws (Romeo 2 PP fenestrated pedicle screws, Spineart, Geneva, Switzerland) were placed with concentric angulation and then were checked with fluoroscopy for proper positioning. Once all pedicle screws were placed, screw augmentation was performed. Augmentation with PMMA was used in all patients in whom we observed bone fragility during screw placement, even when bone density as measured on dual energy $\mathrm{x}$-ray absorptiometry was not less than -2.0 .

Vertecem V+ (DePuy Synthes, Leeds, United Kingdom), a ready-to-use cement, was used for augmentation. After the cement was transferred into syringes, injection was begun with the fluoroscope's $\mathrm{C}$-arm in the lateral projection. We used a stepwise injection technique, closely monitoring cement flow in real time. If we observed cement leakage or uncontrolled cement flow, we stopped the injection immediately. We injected a mean of $3 \mathrm{~mL}$ of cement per screw. Once augmentation was finished, we completed instrumentation and then used a dynamometric wrench for tightening. Bone grafting was done with allografts.

Most patients were allowed to start walking on the second day after surgery, using a soft lumbar brace for comfort. Their braces were removed 6 to 8 weeks later. Prophylactic intravenous antibiotics were given before surgery and then again at 24 hours after surgery. Patients were then moved to our institution's bone metabolism unit for osteoporosis treatment.

\section{Clinical and Radiologic Follow-Up}

Outpatient revisions were made at 1, 3, 6, and 12 months after surgery, and then every year.

\section{Statistical Analysis}

Frequency statistics were used to characterize patient demographics and treatment variables. Clinical outcome scores were evaluated with paired $t$ tests using SPSS (version 19.0, IBM, Armonk, New York). Statistical significance was defined as $P$ $<.05$.

Our study protocol was approved by our institution. All participants provided written evidence of their consent.

\section{RESULTS}

Eighty-nine consecutive patients (59 women and 30 men) older than 67 years (mean age, 78 years; range, 67-88 years) with previous lumbar instability or who needed aggressive decompression underwent spine fusion with PMMA-augmented cannulated pedicle screw instrumentation at some point between October 2015 and February 2018 at our institution. We placed a total of 390 screws in a total of 195 vertebrae. Seventy-two patients underwent 2- 
Table. Epidemiological data.

\begin{tabular}{ll}
\hline Parameter & \multicolumn{1}{c}{ Finding } \\
\hline Sex & 59 females, 30 males \\
Age, mean (range), y & $78(67-88)$ \\
Functional ASA status, n (\%) & \\
$\quad$ II & $61(68)$ \\
$\quad$ III & $28(32)$ \\
Body mass index, mean (range), $\mathrm{kg} / \mathrm{m}^{2}$ & $28.8(19-38)$ \\
Lumbar DEXA $t$ score & $-2.3(-1.6$ to -4.1$)$ \\
\hline
\end{tabular}

Abbreviations: ASA, American Society of Anesthesiologists; DEXA, dual energy $\mathrm{x}$-ray absorptiometry.

level fusion, and 17 underwent 3-level fusion. We continued prospectively collecting data for all patients for a mean of 25 months (range, 12-40 months) after surgery. Epidemiological data are shown in the Table.

Study participants demonstrated a significant improvement in multiple clinical outcomes scores from preoperative to most recent follow-up evaluation (Figure). The average VAS back pain score decreased from 8.2 before surgery to 3.6 by 6 months afterward, a significant improvement $(P<$ $.001)$, maintained at 1 year. The average VAS leg pain score decreased from 6.8 to 2.1 , a significant improvement $(P<.001)$. The average ODI decreased from 65.8 to 36.0 by 6 months after surgery and then to 25.4 by 1 year, a significant improvement $(P<.001)$. No statistically significant differences were observed between values at the 12-month point. According to the criteria of the US Food and Drug Administration for significant functional improvement (an increase of $\geq 15$ points on the ODI scale), $91 \%$ of our patients had satisfactory result. Regarding the last 2 COMI items (related to patient satisfaction with clinical results), $87 \%$ of our patients were satisfied or very satisfied in by the time of their final follow-up examination.

Fusion rates revealed that only 1 patient $(1.1 \%)$ presented with radiological pseudoarthrosis at 1 year follow-up with breakage of a pedicle screw, which made revision surgery necessary for the addition of an anterior cage and bone graft. No bone-cement radiolucency was observed. There were no instances of pullout or hardware failure, and instances of adjacent vertebra fractures. Six patients $(6.7 \%)$ presented with progressive adjacent disc degeneration. All of those presented with an associated increase in pain and a decreased function score; $2(2.3 \%)$ required revision surgery.

Surgery-related complications were observed in 4 patients $(4.4 \%): 3(3.3 \%)$ sustained dura tears during the procedure, and $1(1.1 \%)$ had postoperative contralateral radicular pain that made revision surgery necessary.

Cement leakage was observed in $27(12.2 \%)$ of cemented vertebrae. We found type B leakage (epidural leakage) in 10 vertebrae $(4.5 \%)$, type $\mathrm{S}$ leakage (lateral venous leakage) in 21 vertebrae $(9.5 \%)$, and type $\mathrm{C}$ leakage in 1 vertebra. There were no instances of disc leakage.

During follow-up, we noted deep subacute infections in 6 patients $(6.7 \%)$. All of them needed revision surgery but not instrumentation removal; they were treated with intravenous antibiotics for at least 6 weeks, which resolved their infections.

There were no major complications related to surgery.

\section{DISCUSSION}

Spine surgeons treat many patients with aging spines, and in patients who have DSD, a loss of bone stock makes repair more difficult. Performing osteosynthesis in these patients can be difficult because of osteoporosis and comorbidities that increase complication rates. $^{23}$ Furthermore, in people older than age 65 years, rates of mechanical implant failure and of pseudarthrosis are higher. Various techniques have been described for decreasing those risks. Among them, the use of PPSs has been demonstrated to be effective and to provide spine security in these patients. ${ }^{17}$ In fact, with the use of this instrumentation, advanced age is not a contraindication to surgical treatment, and thus the rates of surgical procedures in these patients have increased dramatically since about the year $2000 .^{14}$

In our study, we analyzed the clinical results of using second-generation PPSs with second-generation PMMA. We found that this combination provides increased durability, providing excellent fixation even in weak bone. It provides excellent leverage, rigidity, and tactile feedback with decreased leakage. The results show a significant improvement in function and lumbar and leg pain relief with a high rate of satisfaction, similar to findings in other series concerning DSD in younger patients. $^{24}$

Continuous fluoroscopy performed during cementation makes it possible to identify the trabecular pattern and to stop cementation a when cement leak occurs. The rate is lower with fluoroscopy than leakage rates described in the management of osteoporotic vertebral fractures, ${ }^{25}$ with a higher 


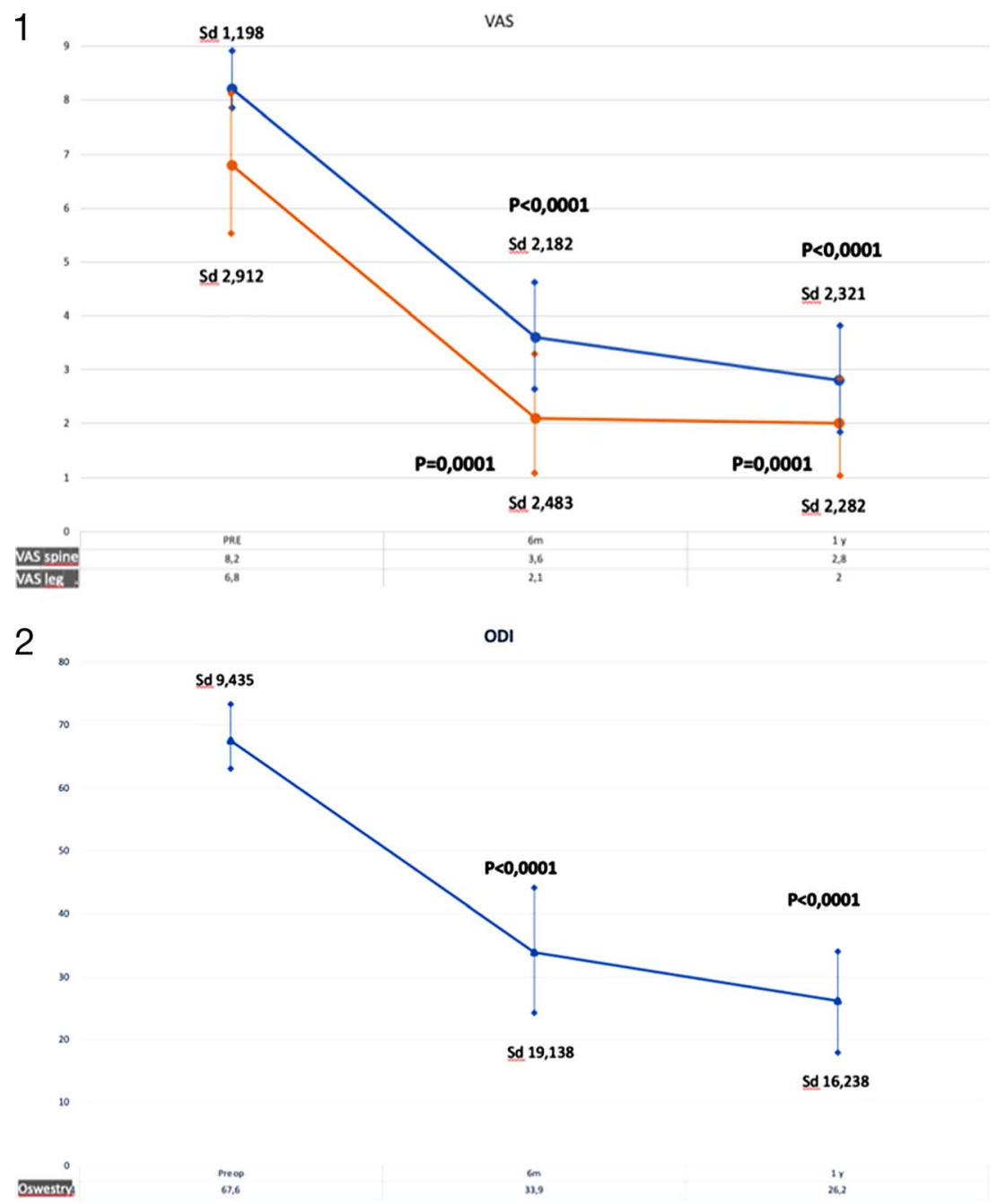

Figure. Patients' scores during the postoperative follow-up period on the visual analog scale (VAS) and the Oswestry Disability Index (ODI).

incidence of type B leakages, because the vertebral height is intact. ${ }^{26}$ The use of augmented secondgeneration perforated pedicle screws decreases significantly the rate of leakages compared with previous studies. ${ }^{16}$ Some authors have suggested that there is a relationship between cementation and the fracture of adjacent vertebrae. ${ }^{27}$ However, we did not have any fractures in our series.

A high rate of fusion in radiological and CT control participants, with only a $1 \%$ rate of pseudoarthrosis, confirms that good stability is achieved with rigid instrumentation when good bone anchorage is ensured.

Many authors have reported a high incidence of complications in instrumented fusion in older patients, especially when they are older than 69 years of age. ${ }^{28}$ Associated comorbidity in those patients is also correlated with complications and adverse outcomes after lumbar surgery. ${ }^{29,30}$ Complications in our series were due not to instrumen- tation but to the surgical procedure and the patient's profile. It is of the utmost importance to explain to patients the risks of this surgery.

Some of our patients developed degenerative disc disease adjacent to the level of fusion, sustaining some functional impairment. This finding correlates with other authors' findings in older patients, even when lower-stress dynamic stabilization is used. ${ }^{24}$ Additional research should be done to determine the factors associated with adjacent disc disease.

\section{CONCLUSION}

The results of our study are encouraging. The use of a cemented rigid instrumentation in patients with lumbar instability maintains clinical improvement and radiological stability over time. Augmentation with PMMA and PPSs is a safe and effective technique and may be a good alternative to other methods for improving spine fixation. 


\section{ACKNOWLEDGMENT}

Medical editor Katharine O'Moore-Klopf, ELS (East Setauket, New York) provided professional English-language editing of this article.

\section{REFERENCES}

1. Zaina F, Tomkins-Lane C, Carragee E, Negrini S. Surgical versus non-surgical treatment for lumbar spinal stenosis. Cochrane Database Syst Rev. 2016;1(1):CD010264. https://doi.org/10.1002/14651858.CD010264.pub2

2. Lurie J, Tomkins-Lane C. Management of lumbar spinal stenosis. BMJ. 2016;352:h6234. https://doi.org/10.1136/bmj. h6234

3. Melancia JL, Francisco AF, Antunes JL. Spinal stenosis. Handb Clin Neurol. 2014;119:541-549. https://doi.org/10.1016/ B978-0-7020-4086-3.00035-7

4. Tetreault L, Goldstein CL, Arnold P, et al. Degenerative cervical myelopathy: a spectrum of related disorders affecting the aging spine. Neurosurgery. 2015;77(suppl 4):S51-S67. https://doi.org/10.1227/NEU.0000000000000951

5. Sivasubramaniam V, Patel HC, Ozdemir BA, Papadopoulos MC. Trends in hospital admissions and surgical procedures for degenerative lumbar spine disease in England: a 15-year time-series study. BMJ Open. 2015;5(12):e009011. https://doi.org/10.1136/bmjopen-2015-009011

6. O’Lynnger TM, Zuckerman SL, Morone PJ, Dewan MC, Vasquez-Castellanos RA, Cheng JS. Trends for spine surgery for the elderly: implications for access to healthcare in North America. Neurosurgery. 2015;77(suppl 4):S136-S141. https:// doi.org/10.1227/NEU.0000000000000945

7. Ishimoto Y, Yoshimura N, Muraki S, et al. Associations between radiographic lumbar spinal stenosis and clinical symptoms in the general population: the Wakayama Spine Study. Osteoarthritis Cartilage. 2013;21(6):783-788. https://doi. org/10.1016/j.joca.2013.02.656

8. Esses SI, Sachs BL, Dreyzin V. Complications associated with the technique of pedicle screw fixation. A selected survey of ABS members. Spine. 1993;18(15):2231-2238. https://doi.org/ 10.1097/00007632-199311000-00015

9. Polly DW Jr, Orchowski JR, Ellenbogen RG. Revision pedicle screws. Bigger, longer shims - what is best? Spine. 1998;23(12):1374-1379. https://doi.org/10.1097/00007632-1998 06150-00015

10. von Strempel A, Kühle J, Plitz W. [Stability of pedicle screws. 2: maximum pullout force with reference to bone density] [German]. Z Orthop Ihre Grenzgeb. 1994;132(1):82-86.

11. Wittenberg RH, Lee KS, Shea M, White AA 3rd, Hayes WC. Effect of screw diameter, insertion technique, and bone cement augmentation of pedicular screw fixation strength. Clin Orthop Relat Res. 1993;(296):278-287. https://doi.org/10.1097/ 00003086-199311000-00045

12. Pfeifer BA, Krag MH, Johnson C. Repair of failed transpedicle screw fixation. A biomechanical study comparing polymethylmethacrylate, milled bone, and matchstick bone reconstruction. Spine. 1994;19(3):350-353. https://doi.org/10. 1097/00007632-199402000-00017

13. Tan JS, Kwon BK, Dvorak MF, Fisher CG, Oxland TR.
Pedicle screw motion in the osteoporotic spine after augmentation with laminar hooks, sublaminar wires, or calcium phosphate cement: a comparative analysis. Spine. 2004;29(16):1723-1730. https://doi.org/10.1097/01.BRS.000013 4569.63542 .49

14. Renner SM, Lim TH, Kim WJ, Katolik L, An HS, Andersson GB. Augmentation of pedicle screw fixation strength using an injectable calcium phosphate cement as a function of injection timing and method. Spine. 2004;29(11):E212-E216. https://doi.org/10.1097/00007632-200406010-00020

15. Schmoelz W, Heinrichs CH, Schmidt S, et al. Timing of PMMA cement application for pedicle screw augmentation affects screw anchorage. Eur Spine J. 2017;26(11):2883-2890. https://doi.org/10.1007/s00586-017-5053-3

16. Piñera AR, Duran C, Lopez B, Saez I, Correia E, Alvarez L. Instrumented lumbar arthrodesis in elderly patients: prospective study using cannulated cemented pedicle screw instrumentation. Eur Spine J. 2011;20(S3 suppl 3):408-414. https://doi.org/10.1007/s00586-011-1907-2

17. Fairbank JC, Pynsent PB. The Oswestry Disability Index. Spine. 2000;25(22):2940-2952. https://doi.org/10.1097/ 00007632-200011150-00017

18. Deyo RA, Battie M, Beurskens AJ, et al. Outcome measures for low back pain research. A proposal for standardized use. Spine. 1998;23(18):2003-2013. https://doi. org/10.1097/00007632-199809150-00018

19. Mannion AF, Elfering A, Staerkle R, et al. Outcome assessment in low back pain: how low can you go? Eur Spine J. 2005;14(10):1014-1026. https://doi.org/10.1007/s00586-005-0911-9

20. Ferrer M, Pellisé F, Escudero O, et al. Validation of a minimum outcome core set in the evaluation of patients with back pain. Spine. 2006;31(12):1372-1379. https://doi.org/10. 1097/01.brs.0000218477.53318.bc

21. Yeom JS, Kim WJ, Choy WS, Lee CK, Chang BS, Kang JW. Leakage of cement in percutaneous transpedicular vertebroplasty for painful osteoporotic compression fractures. J Bone Joint Surg Br. 2003;85(1):83-89. https://doi.org/10.1302/ 0301-620X.85B1.13026

22. Carreon LY, Bratcher KR, Canan CE, Burke LO, Djurasovic M, Glassman SD. Differentiating minimum clinically important difference for primary and revision lumbar fusion surgeries. J Neurosurg Spine. 2013;18(1):102-106. https:// doi.org/10.3171/2012.10.SPINE12727

23. Ponnusamy KE, Iyer S, Gupta G, Khanna AJ. Instrumentation of the osteoporotic spine: biomechanical and clinical considerations. Spine J. 2011;11(1):54-63. https://doi. org/10.1016/j.spinee.2010.09.024

24. Schaeren S, Broger I, Jeanneret B. Minimum four-year follow-up of spinal stenosis with degenerative spondylolisthesis treated with decompression and dynamic stabilization. Spine. 2008;33(18):E636-642. https://doi.org/10.1097/BRS. $0 \mathrm{~b} 013 \mathrm{e} 31817 \mathrm{~d} 2435$

25. Lee IJ, Choi AL, Yie MY, et al. CT evaluation of local leakage of bone cement after percutaneous kyphoplasty and vertebroplasty. Acta Radiol. 2010;51(6):649-654. https://doi. org/10.3109/02841851003620366

26. Tomé-Bermejo F, Piñera AR, Duran-Álvarez C, et al. Identification of risk factors for the occurrence of cement leakage during percutaneous vertebroplasty for painful osteoporotic or malignant vertebral fracture. Spine. 2014;39(11):E693-E700. https://doi.org/10.1097/BRS.0000000000000294 
27. Uppin AA, Hirsch JA, Centenera LV, Pfiefer BA, Pazianos AG, Choi IS. Occurrence of new vertebral body fracture after percutaneous vertebroplasty in patients with osteoporosis. Radiology. 2003;226(1):119-124. https://doi.org/ 10.1148/radiol.2261011911

28. Daubs MD, Lenke LG, Cheh G, Stobbs G, Bridwell KH. Adult spinal deformity surgery: complications and outcomes in patients over age 60. Spine. 2007;32(20):2238-2244. https://doi. org/10.1097/BRS.0b013e31814cf24a

29. Raffo CS, Lauerman WC. Predicting morbidity and mortality of lumbar spine arthrodesis in patients in their ninth decade. Spine. 2006;31(1):99-103. https://doi.org/10.1097/01. brs.0000192678.25586.e5

30. Li G, Patil CG, Lad SP, Ho C, Tian W, Boakye M. Effects of age and comorbidities on complication rates and adverse outcomes after lumbar laminectomy in elderly patients. Spine. 2008;33(11):1250-1255. https://doi.org/10.1097/BRS. 0b013e3181714a44
Disclosures and COI: The authors received no funding for this study. L. Alvarez-Galovich is a consultant at ZimmerBiomet, Spineart and Nuvasive.

Corresponding Author: Luis Alvarez-Galovich, MD, Spine Service, Fundación Jimenez Diaz, Avenida Reyes Católicos no. 2, CP 28040, Madrid, Spain. Phone:+34 91 5495544; Email: lalvarez@fjd.es.

Published 11 November 2020

This manuscript is generously published free of charge by ISASS, the International Society for the Advancement of Spine Surgery. Copyright (c) 2020 ISASS. To see more or order reprints or permissions, see http://ijssurgery.com. 